\title{
Expanding Historical Theological Perspectives through Transdisciplinary Meta-methodological Engagement
}

\section{Peter Houston}

https://orcid.org/0000-0002-0444-9871

University of Stellenbosch

Progress.peters@gmail.com

\section{Abstract}

Transdisciplinarity emerged at the end of the twentieth century and has come to be conceived of as a meta-methodology that seeks to transcend the different methodologies of segregated disciplines. The meta-methodology of transdisciplinarity finds expression in four different frameworks advanced by Rimondi and Veronese. This paper will expand historical theological perspectives by engaging with this transdisciplinarity meta-methodology. Since transdisciplinarity inherently goes beyond any one discipline, it can therefore influence historical theology without becoming it, and vice versa. Transdisciplinarity is set to increasingly influence theology with transdisciplinary theologians seeking to perceive more clearly the boundaries and potentialities of theological reflection.

Keywords: historical theology; transdisciplinarity; environmental theology; complexity

\section{UNISA}




\section{Background}

The term "transdisciplinarity" was formulated by Jean Piaget in 1970 during his discussions with astrophysician, Erich Jantsch, and the mathematician, André Lichnerowicz, at an international conference held in France, L'Interdisciplinarité: Probleme d'enseignement et de Recherche dans les Universités (Rimondi and Veronese 2018, 261). Piaget, together with these scholars from different disciplines, raised a concern regarding the limitations of contemporary sciences (Kroeze, Travica, and Van Zyl 2019, 17). A transdisciplinary symposium was held in Venice in 1986 and a Centre for International Research and Transdisciplinary Studies established in France in the same year (Rimondi and Veronese 2018,261). Portugal hosted the first International Congress on Transdisciplinarity in 1994, which issued the Charter of Transdisciplinarity (Rimondi and Veronese 2018, 261).

It is important to discuss in some depth how transdisciplinarity relates to other notions such as disciplinarity, multidisciplinarity and interdisciplinarity. A fundamental shift took place at the threshold of modernity with the birth and development of modern science. This raised the need for the systematisation of knowledge and disciplines (Rimondi and Veronese 2018, 257). Science specialised in various academic disciplines from the eighteenth century to the Second World War and became associated with industry as applied research (Rimondi and Veronese 2018, 257). Montuori $(2013,213$ ) argues that:

... modernity has been described as the Machine Age. With the Machine Age came what we might call Machine Organization and Machine Thinking. Machine Thinking was appropriate for dealing with machines. Machines, with all their power and novelty, were naturally the key metaphor of the Industrial Age. How do you begin to understand how a machine is put together? By taking it apart. This same process also works for living systems, but of course when one takes a living system apart, it rapidly tends to lose a key quality. Something was missing.

Reductionism was key to Machine Thinking, with the belief that the best way to understand a phenomenon was to reduce it to its component parts (Montuori 2013, 217). But the problems with the reductionist approach were manifold and became apparent towards the end of the twentieth century, with the growing scale and complexity of problems facing humanity that could not adequately be addressed with notions of disciplinarity.

\section{Disciplinarity}

Scholz, Mieg, and Oswald $(2000,478)$ define "disciplinarity" as the label for knowledge production within a single subject area. Knowledge production has been institutionally categorised under the three main domains of natural sciences, humanities and social sciences. Physics, chemistry and biology are subjects of the natural sciences. However, added to this is a sub-category of earth sciences that is comprised of, inter alia, geology, 
oceanography, meteorology, hydrology and geomorphology. Ancient and modern languages, literature, philosophy, history, archaeology, anthropology, law, politics and religion are examples of subjects in the humanities. The social sciences include anthropology, economics, management sciences, media studies, political science, and psychology. Then there are the life sciences, which include zoology, ecology, botany, genetics, medicine and also biology. The challenge of creating and maintaining bounded knowledge systems is apparent, even at this classification stage with subjects sitting under different domains. This is true of theology where theological specialisations abound. Canale $(2001,367)$ notes that:

Modernity has prompted not only a variety of theological methodologies, but also the inception of a variety of independent disciplines. The amount of knowledge has grown to the point that individuals are forced to choose a field, an area, and even a topic of specialization. Most thinkers and scholars tend to specialize within one discipline and become unfamiliar with the rest. As a result of scholarly specialization communication between various theological disciplines has become increasingly difficult.

Perhaps fundamentally, all knowledge is a human construct. It is not only the social world of social science and the humanities that are human constructs. It also applies to the understanding of the physical world on which a priori categories of the human mind are impressed during the process of sense-making (Kroeze et al. 2019, 13). Kroeze et al. $(2019,16)$ argue that:

A disciplinary approach indeed compels complying with the rules of legitimate subjects of study and acceptable research methods. While deepening the mind on the one hand, a discipline delineates and constrains it, on the other.

In a negative sense, De Lange $(2007,46)$ has noted that:

... disciplines are regarded as inward looking, insistent on maintaining the status quo while allowing and controlling limited access to the discipline. They jealously guard their own methodologies and tend to work in small areas of specialisation.

Given the above, the need for other approaches has subsequently emerged.

\section{Multidisciplinarity}

Multidisciplinarity is the coordinated effort of different disciplines to solve a shared problem each from their own perspective (Politi 2019, 238). Each discipline operates autonomously and collaboration does not lead to changes in the existing disciplinary or theoretical structures (Scholz et al. 2000, 478). Some attempt may be made to find terminology that is common to all (Gibbons et al. 1994, 28). However, having common terms is not the same as having a common understanding of those terms. For example, the term "ecosystem" means one thing in ecology and another thing in knowledge management. Because disciplinarity tends toward a closed philosophy, 
multidisciplinarity only opens up ontology in a mechanical manner without true knowledge integration (Kroeze et al. 2019, 18).

\section{Interdisciplinarity}

Interdisciplinarity is defined as the integration of different disciplines at a theoretical or methodological level (Politi 2019, 238). It features the crossing of boundaries between different sciences and the fusion of concepts and methods from different disciplines (Scholz et al. 2000, 478). Knowledge integration between several disciplines is the keyelement that distinguishes interdisciplinarity from other forms of poly-disciplinary research (Kroeze et al. 2019, 18; Politi 2019, 238). Unlike disciplinarity and multidisciplinarity, interdisciplinarity does not require fixed rules and specific methodologies. Where researchers seek to establish general rules and methods of interdisciplinarity, it is the residual and conditioned tendency to create disciplines with relatively stable and well-defined boundaries (Politi 2019, 246). Interdisciplinarity seeks to push and even break such boundaries.

Thinking collectively about complex knowledge problems, whether looking to the future or studying the past, requires what Lélé and Norgaard $(2005,67)$ have described as crossing boundaries both horizontally (across disciplines) and vertically (across experts, policymakers, practitioners, and the public). This adds yet more levels of complexity to the interdisciplinary endeavour. But Lélé and Norgaard $(2005,968)$ have gone further to identify four major barriers to interdisciplinarity:

1. The problem of values being embedded in all types of inquiry and at all stages: in the choice of questions, theoretical positions, variables, and style of research.

2. Researchers in different disciplines study the same phenomenon but differ in their theories or explanatory models (and underlying assumptions).

3. Assumptions are made of the Other, fundamental assumptions of how other disciplines work.

4. Society interacts with and creates incentives or disincentives for interdisciplinary research and consequently the production of interdisciplinary knowledge.

The barriers can also be internal to disciplines (or individual researchers within disciplines) seeking to embrace interdisciplinarity.

Academic communities are constantly defining themselves or reinforcing why their knowledge is credible. Such active communities tout the strengths of their approach to truth and reassert the superiority of their answers. Scholars who drift too far from commonly held characteristics of the community - perhaps in the assumptions they make or their orientation with respect to those they serve, and hence in the nature of the claims about truth that they make - are actively defined as being outside of the 
community (Lélé and Norgaard 2005, 973). Pioneers and participants of interdisciplinary and transdisciplinary research must overcome these various barriers, biases and prejudices.

Notwithstanding all this, Rimondi and Veronese $(2018,261)$ assert that "in the effort to overcome the current fragmentation of knowledge, neither the multidisciplinary nor the interdisciplinary approach can be considered as effective methodological solutions since they are based on simple comparison or interaction of disciplinary approaches and do not seem to achieve profound integration. Hence the need for transdisciplinarity."

\section{Transdisciplinarity}

Transdisciplinarity is an idea whose time has come, the implications of which are potentially revolutionary to academia (Montuori 2013, 222, 226). It emerged at the end of the twentieth century as critiques were presented on the pitfalls of the compartmentalisation of knowledge, a globalised economy, the ethics of research, and not least, the environmental crisis (Bernstein 2015). Transdisciplinarity resulted as a reaction to the rigid specialisations inherent to the disciplinary approach and which today's academia rests on (Kroeze et al. 2019, 16). Transdisciplinarity is sometimes referred to as "perfected interdisciplinarity" where concepts are transferred from one discipline to another (Scholz et al. 2000, 478). Transdisciplinarity is an approach that seeks to transcend the boundaries between disciplines and questions the very idea of scientific disciplines (Politi 2019, 238; Scholz et al. 2000, 478). It is research that goes across the boundaries of many disciplines, purposively going beyond them (Mokiy 2019, 250). It recognises that the boundaries of disciplines are influenced by both the internal and external environments of the discipline (Loubser 2015).

Yet, the well-established divisions between disciplines have in many respects thinned progressively in recent years and have given rise to more labile boundaries (Rimondi and Veronese 2018,259). The task of a transdisciplinary researcher is to determine the nature of these boundaries and how they can productively function by creating transdisciplinary conceptual overlaps (Rimondi and Veronese 2018, 258). This can open up the possibility of fruitful collaboration that produces new knowledge and more constructive interactions between existing disciplines (Rimondi and Veronese 2018, 260). Transdisciplinarity is a completely different way of thinking about knowledge and offers the opportunity to investigate the fundamental assumptions about knowledge, the generation of knowledge and research (Rimondi and Veronese 2018, 265).

That said, all these different kinds of activities - multidisciplinarity, interdisciplinarity and transdisciplinarity - can be conceived of as being on a continuum. Politi $(2019,239)$ argues that "research may begin with the involvement of different disciplines, which, with time, may get integrated and, eventually, may end up breaking disciplinary boundaries." This is perhaps why the terms "interdisciplinarity" and "transdisciplinarity" are sometimes used interchangeably, although not without 
controversy, given the extent to which their significant differences have been defined previously. Kroeze et al. $(2019,22)$ note that both approaches "deconstruct disciplinary premises with the goal of overcoming disciplinary self-boundedness." Furthermore, both interdisciplinarity and transdisciplinarity enrich contributing disciplines by "challenging and expanding their boundaries that may even lead to paradigm shifts" (Kroeze et al. 2019, 24). The result is research that reshapes the traditional borders of disciplines, generating novel scholarly ideas and opening up new fields for research (Kroeze et al. 2019, 17).

\section{Transdisciplinary Meta-methodology and Historical Theological Perspectives}

The dialogue between theology and the natural sciences has a complex history, which includes the ever-changing methodological basis of that dialogue through the ages (De Lange 2007, 44). Yet, today, scientists and theologians have solid reasons to talk to each other since; despite the historical schism, they face some common pressing questions of the future (Stork 2013, 26). There is a need within theology for "a more complex historical understanding of the interaction of socio-cultural and natural processes" (Bergmann 2021, 166). Furthermore, human solidarity with nature can become the starting point of the new theological and scientific reflection that contemplates questions of ultimacy (Stork 2013,27). The critique of interdisciplinarity and transdisciplinarity presented previously equally applies to theology, as a whole, and the discipline of historical theology, in particular. Fruitful attention can be paid to dialogical interactions with other knowledge domains such as science. In so doing, boundaries can be pushed and crossed and opportunity afforded for a completely different way of thinking about theological knowledge and even the fundamental assumptions about that knowledge.

Transdisciplinarity is conceived as meta-methodology which seeks to transform or transcend the different methodologies of the various disciplines (Rimondi and Veronese 2018, 261). Connections are sought within the total knowledge of an assumed one ordered world without stable boundaries between disciplines (Rimondi and Veronese 2018, 261). Participants in transdisciplinary research must, therefore, "step outside conceptual, theoretical, and methodological confines of their own discipline" (Hunt and Thornsbury 2014, 341). The aim of transdisciplinarity is to restore a unity of knowing. But it is important to note, this does not mean "abolishing scientific knowing (or any other form of knowing) but to see all forms of knowing as complementary, making up one complex reality" (Dieleman 2013, 71).

Although the problem of complexity is typically ascribed to both the natural sciences and social sciences, this complexity is also found in theology. Loubser (2015) argues this point:

Transdisciplinary theologians recognise that the issues regarding faith, religion and spirituality are complex issues and require solutions that cannot be developed in a single 
discipline. This is because faith, religion and spirituality are complex and dynamic concepts that influence and are influenced by emotional, intellectual, economic, ecological, political, communal and personal aspects of people's lives.

In interdisciplinary research, theologians can cross the boundaries of their respective disciplines and investigate different aspects of a transversal issue, while protecting the integrity of their disciplines (Loubser 2016). Transdisciplinary theological research, however, is not able to fit studied realities into nicely demarcated disciplines (Loubser 2016). Yet it is precisely because of this - through intentional interactions with scholars from other disciplines - that transdisciplinary theologians "come to see the boundaries, weaknesses, strengths and potential of theological reflection" (Loubser 2017). In this context, transdisciplinarity is characterised by that which goes beyond any one discipline and can therefore influence historical theology without becoming it. The meta-methodology of transdisciplinarity finds expression in four different frameworks: I, II, III, IV.

\section{Transdisciplinarity-I}

Transdisciplinarity-I shows a close connection to multidisciplinarity research (Rimondi and Veronese 2018, 264). Rimondi and Veronese $(2018,264)$ state that:

This type of transdisciplinarity is based on the formal interconnection of individual disciplines, thus contributing to the formation of logical meta-frames through which knowledge can be integrated at a higher level of abstraction than it does in interdisciplinarity.

Take, for example, water. The existence of water is the basis for life on earth. It is the subject of study for many disciplines. The hydrological cycle is studied by hydrologists and geohydrologists at a terrestrial level, by meteorologists as it relates to precipitation and by climatologists when applied to a longer time period. Water is a crucial factor in slope processes in geomorphology. As a general resource, water is studied by geographers, economists, and agricultural scientists. It is important to technology, engineering and manufacturing. Bernstein adds: "There are even political aspects to an important resource such as water, shortages of which can lead to famine, war, revolution, or other vast socio-political changes. One could continue ad infinitum about the innumerable facets of water that need to be studied" (Bernstein 2015).

Even within the broad discipline of theology, water is studied variously as a subject. The woman at the well can be a subject of New Testament study or from a gendered or social-justice perspective or Christian ethics. Just Water: Theology, Ethics, and the Global Water Crisis (2014) by Christiana Z. Peppard is one such example. Proverbs 5:15-20 has been looked at by Kivatsi Kavusa (2017) as a subject of Old Testament inquiry but relating it to the water crises experienced in present-day Africa. Water as ritual and symbolism is studied variously by liturgists, missiologists and practical 
theologians. Structural variety is therefore required by, and is a consequence of, the manifold ends that are involved in the theological enterprise (Canale 2001, 376).

Unifying or traversing all these theological approaches, environmental theology has emerged at the forefront of interdisciplinarity and more recently, transdisciplinary endeavours both within and without theology. Ernst Conradie is recognised as a pioneer of environmental theology in South Africa, and its interdisciplinary nature and dialogue. However, recently scholars such as Gys Loubser have begun suggesting that Conradie's work can also be described as transdisciplinary theology (Loubser 2016). Loubser argues that Conradie:

... recognises the knower in generating knowledge and engages issues disclosed and addressed through lived experience. Furthermore, he draws on numerous disciplines and appreciates that disciplines are open and have histories. Most importantly, he draws on environmental conversations to question theological assumptions and enrich theology as a discipline ... we can draw on and critique Conradie as a transdisciplinary theologian. (Loubser 2016)

This leads to a discussion of Transdisciplinarity-II, which recognises that "the reasons for the inquiry, the philosophical and methodological approaches that are brought to bear, these are all brought by the inquirer to the inquiry-by somebody from somewhere" (Montuori 2013, 205). Conradie is open about this process, as is environmental theology by its very nature. If environmental theology and/or some of its eminent inquirers are coming to be considered as transdisciplinarian, then it follows that the historical theological inquiry needs to be able to be cognisant of this too and be able to push and transcend the very same boundaries.

\section{Transdisciplinarity-II}

Reflective action is a way to explore reality with the intention of seeking greater understanding but unlike the classical cognitive and analytical mode, it is rooted in conscious sensitivity, intuition as well as analytical rationality (Dieleman 2013, 72). It is "simultaneously intellectual and analytical, constructive and creative, social and communicative as well as sensorial and emotional. It therefore results in a more comprehensive understanding of oneself and of the world in general" (Dieleman 2013, $75)$.

Transdisciplinarity-II acknowledges the inner connection with a researcher's personal experience (Rimondi and Veronese 2018, 264). This level of transdisciplinarity integrates the inquirer into the inquiry and affirms the role of reflective action. Montuori $(2013,205)$ says "it starts with the basic assumption that every inquiry is conducted by an inquirer, a person with a history, a social and historical context, beliefs, values, biases, blind spots, ways of thinking, and so on." Transdisciplinary research involves getting to know other selves and for transdisciplinary theologians, this means understanding disciplinary contexts and histories as well as the selves that generated the 
knowledge (Loubser 2015). This demands that transdisciplinary theologians develop "exceptional empathic skills" (Loubser 2015).

Historical theology is well placed in this regard. It affirms and recognises that every history has a broader context in which theological ideas were formed and these realities need to be treated empathetically. Ideas were shaped by people, or inquirers, to use the language of Montuori, who were themselves part of and shaped by their context. They did not remain unaffected and a study of theologians can demonstrate how an individual's thinking changed over time and was adapted by successive generations. Transdisciplinary theologians also appreciate that theologies are constituted by their relationship to their environments, and influence their environments, which means that theologies evolve through time and result in complex histories (Loubser 2017). Likewise, historical theology is the study of history that links us to the complex circumstances surrounding the development of different theologies over time. An important dimension in this remains the role of the inquirer, which Montuori (2013, 205) develops further by arguing:

In order to understand the subject of my inquiry, I also need to pay attention to who is doing this inquiry, and understand myself. Every inquiry is therefore potentially an avenue for self inquiry. And furthermore, the process of inquiry and the knowledge that is used for, and being generated by, the inquiry is not somehow "external" to the inquirer. The inquirer is not transparent, not a bystander.

This same reality is made plain in Williams's treatment of history, where he speaks of the need for reflecting more closely on our theological indebtedness to the people from the past (Williams 2005). Self-inquiry, while not explicit in Bromiley's historical theological methodology, is an important component. Each of the five approaches that Bromiley outlines requires an inquirer of historical theology to acknowledge that they are part of the inquiry and that they therefore determine the process in some way. What is selected, dwelt on or neglected in a rapid survey or multi-volume study or interpretative theses or explanatory study - and especially a selective study-will depend on the interests and expertise of the inquirer (Bromiley 1978, xxii). Thus, Bromiley posits that both the aim of historical theology and the methodology applied to advance historical theology inherently impose selectivity and contain a certain "arbitrary element in which circumstances and preferences play a major part" (Bromiley 1978, xxiii). Any and all historical theological work therefore needs to make space, and give weight to, the role of the inquirer. Montuori $(2013,206)$ notes that:

This does not mean that now all is subjective, by any means. It does mean that the complex relationship between inquirer and inquiry is being illuminated rather than swept under the carpet. 
Simply put, the nature of the inquirer matters to the inquiry. Montuori $(2013,214)$ concludes his thoughts on transdisciplinarity with a statement that equally applies to historical theology:

The implications of complexity and transdisciplinarity go far beyond a set of tools for academic inquiry. They call for a reflection on who we are, how we make sense of the world, and how we might find ways to embody different ways of being, thinking, relating, and acting in the world.

The implications of the complexity of historical theology also go far beyond a set of tools for academic inquiry, but require a researcher of historical theology to reflect on who they are, how they make sense of the church in the world, and how they might find ways to embody different ways of being, thinking, relating, and acting in relation to the historical advancement of different theologies. Peters $(2014,207)$ argues that, in particular, "Evangelical theologians need to get more serious about the history of ideas, those that pre-date the Christian faith and those that fall further afield included."

Transdisciplinarity-II is no easy task, since inquirers oftentimes have to go contrary to their disciplinary training or as Lélé and Norgaard $(2005,975)$ relate, "participants need to be self-reflective about the value judgments embedded in their choice of variables and models, willing to give respect to and also learn more about the 'other' and able to work with new models and taxonomies used by others."

\section{Transdisciplinarity-III}

The principle of holism lies at the basis of Transdisciplinarity-III (Rimondi and Veronese 2018,264). Holism is a position in philosophy and in science regarding the problem of the relationship between the parts and the whole, where the whole is acknowledged as always being more than the sum of its parts. It is understood as the "philosophy of integrity" (Mokiy 2019, 252). The lesson of holism - that the whole is greater than the sum of the parts - is one of the fundamentals of environmental science. Research can be undertaken in the laboratory, studying materials' strength, or out in the field, investigating hillslope processes in the attempt to model them better or generate more reliable statistical baselines, or over even larger areas and timeframes. Together this knowledge makes up the whole and no one part is sufficient to describe the whole. Furthermore, holism affirms the importance of connectedness and the resultant complexity. Not only is everything connected, but every part is important to the whole.

The Transdisciplinarity-III affirmation of holism not only finds application in philosophy and science, but also in theology. Theological engagement with holism challenges the compartmentalising of personal and public expressions of religion towards an integrating whole-affirming Christian connectedness and holy holism. A transdisciplinary inquirer is, therefore, an "open-minded and holistic thinker who brings disciplinary knowledge into a new synthesis by overcoming its methodological and theoretical bounds" (Kroeze et al. 2019, 27). A historical theological approach that 
embraces transdisciplinarity will be characterised by these same open-minded and holistic attributes.

\section{Transdisciplinarity-IV}

Transdisciplinarity-IV gives expression to the concept of one-centeredness in organising research where the world is hypothesised as "an ordered set of attributes, causes and consequences of the existence of the world, general and particular laws and phenomena, objects and processes, including as well as their properties, connections and interactions at any level of reality" (Rimondi and Veronese 2018, 264). Transdisciplinarity posits that the main condition for the existence of the world is the existence of a universal order in it and that this order manifests itself everywhere (Mokiy 2019, 253). Building on the holism of Transdisciplinarity III, level IV is meant to embolden the notion, described by Mokiy, that "the one and only world is represented as the sum of ordered fragments of space, attributes of information and periods of time that determine the unity of goals and results of the development of phenomena and processes of reality" (Mokiy 2019, 254). This is not a new theoretical or philosophical pursuit. Physicists and cosmologists for decades have sought to come up with an ultimate theory of (almost) everything. But it appears that within these scientific domains, what is emerging is not a single theory but a family of interconnected theories (Hawking and Mlodinow 2010). Bergmann $(2021,173)$ has astutely concluded, "time and history, as well as space and place, always remain transparent for the Triune." While belief in a universal order may be comforting, there is also evidence of chaos and disorder. Therefore, the notion of a universal order being variously advanced and disputed is rather a matter of faith, however confidently it may be espoused within the meta-methodology of transdisciplinarity.

\section{Conclusion}

Transdisciplinarity is not a bounded area of knowledge nor a discipline and must remain changing and Other in order to be trans. It is the in-between area, the middle area, in which "the nature of the relationships between multiple domains of knowledge can be explored and unveiled" (Rimondi and Veronese 2018, 265). Historical theology in dialogue with transdisciplinarity can emerge as this middle area in theology, investigating the nature of relationships within the different theological domains, and how they have changed over time through interactions with other disciplines and historic contexts. Perhaps, nowhere is this more evident than in the historical theological investigation of environmental theology, which because of its orientation towards the environmental sciences, lends itself to transdisciplinarity meta-methodologies and therefore benefits from boundary crossing in this regard.

It must be noted, in closing, that transdisciplinarity is a contested academic discourse, with different schools of thought and limited consensus. This can render interactions between transdisciplinarity and theology likewise open to being contested. Furthermore, while some theologians (such as Conradie) are being identified as being 
transdisciplinary pioneers, very little has been published in relation to theological discourses around transdisciplinarity, resulting in a dearth of theological resources to draw on. Nevertheless, it follows that the trajectory of the evolution of an environmental theological discourse interweaves and tracks that of the sciences itself and the emergence of transdisciplinarity. Consequently, the investigation of the interaction of ideas and methodologies over time, the domain of historical theology, must also come into contact with and be shaped by transdisciplinarity, which to date has not happened. This is both an urgent and important pursuit, for as De Lange $(2007,60)$ argues, "it is up to theologians and scientists alike to rise to this challenge, to work together to improve humankind's understanding of the complex and fragmented reality that it faces in the twenty-first century."

\section{References}

Bergmann, S. 2021. "Theology in the Anthropocene and Beyond?” In Contextual Theology Skills and Practices of Liberating Faith, edited by S. Bergmann and M. Vähäkangas. New York: Routledge. https://doi.org/10.4324/9780429348006.

Bernstein, J. H. 2015. “Transdisciplinarity: A Review of its Origins, Development, and Current Issues.” Journal of Research Practice 11 (1).

http://jrp.icaap.org/index.php/jrp/rt/printerFriendly/510/412.

Bromiley, G. W. 1978. Historical Theology: An Introduction. Grand Rapids, MI: William B. Eerdmans Publishing Company.

Canale, F. 2001. "Interdisciplinary Method in Christian theology? In search of a Working Proposal." Neue Zeitschrift für Systematische Theologie und Religionsphilosophie 43 (3): 366-389. https://doi.org/10.1515/nzst.2001.006.

De Lange, M. C. 2007. "Reflections on Methodology and Interdisciplinarity in the Postmodern Dialogue between Theology and the Natural Sciences.” Acta Theologica 27 (2): 44-62. https://doi.org/10.4314/actat.v27i2.5499.

Dieleman, H. 2013. "From Transdisciplinary Theory to Transdisciplinary Practice: Artful Doing in Spaces of Imagination and Experimentation." In Transdisciplinary Theory and Practice, edited by B. Nicolescu and A. Ertas. Austin, TX: The Atlas Publishing. https://doi.org/10.22545/2012/00028.

Gibbons, M., C. Limoges, H. Nowotny, S. Schwartzman, P. Scott, and M. Trow. 1994. The New Production of Knowledge: The Dynamics of Science and Research in Contemporary Societies. London, UK: Sage.

Hawking, S., and L. Mlodinow. 2010. "The Elusive Theory of Everything.” Scientific American, 1 October 2010. https://www.scientificamerican.com/article/the-elusive-thoeryof-everything/. 
Hunt, F., and S. Thornsbury. 2014. "Facilitating Transdisciplinary Research in an Evolving Approach to Science.” Open Journal of Social Sciences 2: 340-351.

https://doi.org/10.4236/jss.2014.24038.

Kavusa, K. J. 2017. “An Eco-theological Interpretation of Proverbs 5:15-20 in the Light of Water Crises experienced in Present-day Africa.” Old Testament Essays 30 (3): 707-724. https://doi.org/10.17159/2312-3621/2017/v30n3a10.

Kroeze, J. H., B. Travica, and I. van Zyl. 2019. "Information Systems in a Transdisciplinary Perspective: Leaping to a Larger Stage.” Alternation: Special Edition 24: 9-47. https://doi.org/10.29086/2519-5476/2019/sp24.2a2.

Lélé, S., and R. B. Norgaard. 2005. "Practicing Interdisciplinarity.” BioScience 55 (11): 967975. https://doi.org/10.1641/0006-3568(2005)055[0967:PI]2.0.CO;2.

Loubser, G. M. 2015. "Becoming Transdisciplinary Theologians: Wentzel van Huyssteen, Paul Cilliers and Constantine Stanislavski." HTS Teologiese Studies/Theological Studies 71 (3). https://doi.org/10.4102/hts.v71i3.2901.

Loubser, G. M. 2016. "Being Transdisciplinary Theologians in and beyond Apocalyptic Environments." HTS Teologiese Studies/Theological Studies 72 (4). https://doi.org/10.4102/hts.v72i4.3473.

Loubser, G. M. 2017. “The Dynamics of Theologies: A Transdisciplinary Description.” HTS Teologiese Studies/Theological Studies 73 (3). https://doi.org/10.4102/hts.v73i3.3866.

Mokiy, V. 2019. "Systems Transdisciplinary Approach in the General Classification of Scientific Approaches.” European Scientific Journal 15 (19): 247-258. https://doi.org/10.19044/esj.2019.v15n19p247.

Montuori, A. 2013. "Complexity and Transdisciplinarity: Reflections on Theory and Practice." World Futures: The Journal of Global Education 69 (4-6): 200-230. https://doi.org/10.1080/02604027.2013.803349.

Peppard, C. Z. 2014. Just Water: Theology, Ethics, and the Global Water Crisis. Maryland, NY: Orbis Books.

Peters, G. 2014. "Historical Theology and Spiritual Formation: A Call." Journal of Spiritual Formation and Soul Care 7 (2): 203-209. https://doi.org/10.1177/193979091400700204.

Politi, V. 2019. “The Interdisciplinarity Revolution.” Theoria 34 (2): 237-252. https://doi.org/10.1387/theoria.18864.

Rimondi, G., and M. Veronese. 2018. "Defining the Dialogue between Sciences: A View on Transdisciplinary Perspective in the Human Sciences." Informing Science: The International Journal of an Emerging Transdiscipline 21, 255-268. https://doi.org/10.28945/4115. 
Scholz, R. W., H. A. Mieg, and J. E. Oswald. 2000. "Transdisciplinarity in Groundwater Management: Towards Mutual Learning of Science and Society." Water, Air, and Soil Pollution 123: 477-487. https://doi.org/10.1023/A:1005292328778.

Stork, P. 2013. “A Theologian among Scientists: 'Wisdom' as Interdisciplinary Space for Science and Theology." Compass 26: 22-31.

Williams, R. 2005. Why Study the Past? The Quest for the Historical Church. Grand Rapids, MI: William B. Eerdmans Publishing Company. 